\title{
Experimental and Theoretical Study of Electrical Conductivity of Intermetallic and Nanocomposites: Subzero Temperature Superconductor
}

Harish Kumar ( $\sim$ harimoudgil1@gmail.com )

Dept. of Chem., School of Basic Sci., Central University of Haryana, Mohindergarh 123029 (India) https://orcid.org/0000-0002-8559-2302

Aarti Bhateria

Dept. of Chem., School of Basic Sci., Central University of Haryana, Mohindergarh 123029 (India)

Bhupender Singh

Central Research Facility, Indian Institute of Technology, IIT, Delhi

Pawanvir Kaur

Dept. of Chem., Ch. Devi Lal University, Sirsa -125 055 (India)

\section{Research Article}

Keywords: Nanocomposites, electrical conductivity, subzero temperature superconductor, intermetallic compounds

Posted Date: February 11th, 2021

DOI: https://doi.org/10.21203/rs.3.rs-215710/v1

License: (c) (1) This work is licensed under a Creative Commons Attribution 4.0 International License. Read Full License 


\section{Experimental and theoretical study of electrical conductivity of intermetallic and nanocomposites: Subzero temperature superconductor}

3

\section{Abstract} compounds.

\author{
Harish Kumar $^{\mathrm{a}, *}$, Aarti Bhateria ${ }^{\mathrm{a}}$, Bhupender Singh ${ }^{\mathrm{b}}$, and Pawanvir Kaur ${ }^{\mathrm{c}}$
}

a Dept. of Chem., School of Basic Sci., Central University of Haryana, Mohindergarh 123029 (India)

${ }^{\mathrm{b}}$ Central Research Facility, Indian Institute of Technology, IIT, Delhi

${ }^{c}$ Dept. of Chem., Ch. Devi Lal University, Sirsa -125 055 (India)

* Author for correspondence, harishkumar@cuh.ac.in

https://orcid.org/0000-0002-8559-2302

A comparative study of the electrical conductivity of intermetallic and corresponding nanocomposites at room and the subzero temperature was carried out by experimental and theoretical techniques. Four series of intermetallic compounds (IMCs) and nanocomposites ( $\mathrm{NCs}$ ) of $\mathrm{Al}_{2} \mathrm{O}_{3}, \mathrm{ZnO}, \mathrm{TiO}_{2}$, and $\mathrm{CuO}$ were synthesized by high-temperature reactive synthesis and sol-gel technique, respectively. Heat treatment of NCs was carried out at 100, 200,300, and $400^{\circ} \mathrm{C}$. Characterization of NCs was carried out by UV-visible, FTIR, FE-SEM, and XRD techniques. Computational study (DMol3, CASTEP, Forcite, Reflex, and VAMP) was carried out to study the electronic and optical properties of metal nanoparticles. The influence of heat treatment, the addition of coinage metal and ferromagnetic material, effect of a decrease in temperature on the electrical conductivity of IMCs and NCs were thoroughly investigated. The electrical conductivity of NCs was found to increase with an increase in heat treatment temperature (up to $400^{\circ} \mathrm{C}$ ) and with the decrease in temperature $\left(-70^{\circ} \mathrm{C}\right)$. The addition of Hematite, $\alpha-\mathrm{Fe}_{2} \mathrm{O}_{3}$, and coinage metal do not significantly increase the electrical conductivity of NCs at room temperature. The electrical conductivity of NCs was found to be higher than IMCs and coinage metals. Hence, synthesized NCs can have a large number of potential applications in nanowires, quantum dots, and nano cables with very low resistivity $\left(10^{-6} \Omega \mathrm{m}^{-1}\right)$.

Keywords: Nanocomposites, electrical conductivity, subzero temperature superconductor, intermetallic 
1 Introduction

Nowadays hybrid materials based on metal-metal nanocomposites (NCs) are constantly in demand for their use in sensors, energy storage devices, fuel cells, capacitors, rechargeable battery electrode material, solar panel, electronics, etc. Researchers are constantly working towards the fabrication of room temperature and subzero superconductors as well as high-temperature superconductors. Few metals having a critical temperature, $\mathrm{T}_{\mathrm{c}}$ near to $1 \mathrm{~K}$ like aluminum, titanium, zinc, copper, vanadium, niobium $\left(\mathrm{T}_{\mathrm{c}}=9.2 \mathrm{~K}\right)$, gallium, mercury, indium, tin, and lead become superconductor below their critical temperature. "Recently, superconductivity was observed at a very low temperature in organometallic compounds, perovskite, ceramics, cuprates, semiconductors, iron pnictides, iron chalcogenides, rare earth borocarbides, etc. [1-4]. NCs of different metal oxide shows a high order of conductivity due to their quantum size effects [5,6]. Hybrid materials-based metal oxide NCs have gained much attention due to their advanced functional properties resulting due to their small size. Nanotubes, nanowires, nanorods, quantum dots, nano cables, nanobelts were synthesized by different research groups and their electrical, optical, mechanical, luminescent properties were used in electronic, optical, mechanical, photonics applications [7,8]. Most of the metal oxides like tin oxide, titanium dioxide, tungsten oxide, zinc oxide, alumina, iron oxide shows AC electrical conductivity in the range of intrinsic semiconductors i.e., they show wide-bandgap between valence and conduction band" [9]. To the best of our knowledge, no researchers have so far reported the comparative electrical conductivity of IMC and NCs of Al, $\mathrm{Zn}, \mathrm{Ti}$, and $\mathrm{Cu}$ at $\mathrm{NTP}\left(20^{\circ} \mathrm{C}\right)$, the triple point of water $\left(0.01^{\circ} \mathrm{C}\right)$ and dry ice temperatures both by theoretical and experimental techniques.

In this paper, four series of intermetallic compounds (IMCs) and corresponding metal NCs of aluminum, zinc, titanium, and copper were synthesized by self-propagating high-temperature reactive synthesis and sol-gel technique, respectively. Characterization of IMC and metal NCs was carried out by UV-visible, FTIR, FE-SEM, and XRD techniques. For the first time, computational chemistry (Density Functional Theory) was used to study the electronic and optical properties of synthesized metal oxide nanoparticles, and the same was supported by different experimental techniques. The electrical conductivity of four NCs was compared with corresponding IMCs and coinage metals.

\section{Materials and Methods}

\section{2.1 Materials}

58 AR grade aluminum oxide of $99.997 \%$ purity (CAS No. 1344-28-1) was procured from Sigma-Aldrich Chemicals 59 Pvt. Ltd., Bangalore (India). AR grade titanium dioxide of 99.5\% purity (CAS No. 13463-67-7) was procured from 60 Sigma-Aldrich Chemicals Pvt. Ltd., Bangalore (India). AR grade copper (IV) oxide of percentage purity greater than 61 99\% (CAS No. 1317-38-0) was procured from Himedia Chemicals Pvt. Ltd., Mumbai (India). AR grade zinc oxide 62 of $99.0 \%$ purity (CAS No. 1314-13-2) was procured from Merck Chemicals Pvt. Ltd., Bangalore (India).

\subsection{Methods}

65 Step 1. Synthesis of intermetallic compounds (IMCs)

66 Four series of IMCs of aluminum, zinc, titanium, and copper were synthesized by reactive synthesis method based on 67 Kirkendall effect (Self-propagating High-temperature Synthesis, SHS) followed by sintering process by using 
different compositions of their metal oxides like aluminum, Zinc, Titanium, and Copper. Table 1 shows the composition of four series of IMCs. Different compositions of metal oxides (\%age by mass) were taken for the reactive synthesis of IMCs followed by the sintering process i.e., heating the IMCs at a rate of $5{ }^{\circ} \mathrm{C}$ per min up to a maximum temperature of $600^{\circ} \mathrm{C}$. After that, IMCs were left in the muffle furnace overnight for attaining room temperature.

\section{Step 2. Synthesis of metal nanocomposites (NCs)}

Four series of $\mathrm{NCs}$ of alumina $\left(\mathrm{Al}_{2} \mathrm{O}_{3}\right)$, zinc oxide $(\mathrm{ZnO})$, titanium dioxide $\left(\mathrm{TiO}_{2}\right)$, and copper oxide $(\mathrm{CuO})$ were synthesized by the sol-gel method [10, 11]. $0.5 \mathrm{M}$ solution of $\mathrm{Al}_{2} \mathrm{O}_{3}, \mathrm{ZnO}, \mathrm{TiO}_{2}$, and $\mathrm{CuO}$ were prepared in $500 \mathrm{~mL}$ double distilled water (conductivity $0.5 \mu \mathrm{mhos} / \mathrm{cm}$ ). Few drops of dilute nitric acid were added to make the solution acidic. The solution was labeled as A. 0.1 M oxalic acid and pure ethanol solution were prepared in the ratio of 1:4. The solution was labeled as B. Now, B was added to A drop by drop with continuous stirring (rpm 400) at $70^{\circ} \mathrm{C}$ for 6 h. A jelly-like substance was formed. Kept in an electric oven for drying at $100^{\circ} \mathrm{C}$ for $24 \mathrm{~h}$. Washing was carried out with acetone till $\mathrm{pH} 7$ of washing solution followed by drying at $100^{\circ} \mathrm{C}$ in an electric oven for $24 \mathrm{~h}$. NCs were divided into different parts to perform heat treatment of samples up to $400^{\circ} \mathrm{C}$ by keeping the samples in a muffle furnace and subjected to a uniform heating rate of $5^{\circ} \mathrm{C}$ per min.

\section{Step 3. Synthesis of ferromagnetic Hematite, $\alpha-\mathrm{Fe}_{2} \mathrm{O}_{3}$, and coinage metal $\mathrm{NCs}$}

The $0.5 \mathrm{M}$ solution of iron oxide and $0.5 \mathrm{M}$ solution of silver and copper oxide was added as a dopant to AZTC NCs by the ex-situ method. The purpose of the addition of iron oxide and coinage metal as a dopant in NCs was to see the effect of the introduction of magnetic properties and highly conducting metals (noble metals) on the conductivity of NCs. Table 6 shows the different concentrations of Hematite used in the four metal NCs. Table 7 shows the addition of coinage metal $(\mathrm{Cu}$ and $\mathrm{Ag})$ in the different ratios $(0.5 \mathrm{M})$ to AZTC NCs.

\section{Step 4. Measurement in electrical conductivity and bandgap.}

The optical band gap of four series of metal NCs and IMCs was measured by UV-visible spectroscopy, multi-meter (Jaypee, India Pvt. Ltd.), and LCR meter (HTC digital LCR meter, 4070). The electrical conductivity was measured at room temperature, -18 and $-78{ }^{\circ} \mathrm{C}$. The $-18{ }^{\circ} \mathrm{C}$ temperature was attained by the deep freezer and $-78{ }^{\circ} \mathrm{C}$ was attained by dry ice packs.

For measuring electrical conductivity, metallic wires of IMCs and metal NCs were formed by using mineral oil. Metallic wires were polished using emery papers of different grades (100 to $600 \mu$ ) from both ends. Both the ends were then cleaned with acetone. The diameter and thickness of the metallic wires were measured. For making electrical contact with terminals of the connector, silver paint was applied at both ends. The electrical conductance, capacitance, and resistance of four series of IMCs and NCs were recorded. Table 2 shows four series of metal NCs synthesized by the sol-gel method by making metal salts solution in definite proportion. Table 3 shows the capacitance and electrical conductivity of IMCs and their metal oxide $\mathrm{NCs}$ of $\mathrm{Al}_{2} \mathrm{O}_{3}, \mathrm{ZnO}, \mathrm{TiO}_{2}$, and $\mathrm{CuO}$ measured with the help of a multimeter and LCR meter. Table 4 shows the electrical conductivity by multimeter and LCR meter and optical bandgap calculated by using UV-visible spectroscopy. 


\subsection{Characterization of IMCs and NCs}

Characterization of IMCs and NCs was carried out by FTIR (Make Bruker ATR-IR), UV-visible (Make Shimadzu UV-2600), XRD (Make Brooker D8-Advance, $2.2 \mathrm{~kW} \mathrm{Cu}$ Anode), and FE-SEM (Make FEI FESEM Quanta 200 FEG). Fig. 1 shows UV-visible absorption spectra of four IMCs and NCs. Fig. 2 shows the optical band-gap calculated by Tauc relation with the help of UV-visible spectroscopy. Fig. 3 shows FTIR spectra of AZTC NCs in the range of 550 to $4000 \mathrm{~cm}^{-1}$. FTIR absorption spectra show characteristics absorption peaks in the fingerprint region. Fig. 4 shows the X-ray diffraction pattern of four series of IMCs. Fig. 5 shows the X-ray diffraction pattern of four series of AZTC NCs. The order of crystallinity present in AZTC NCs was investigated by using Bruker X-ray diffractometer using $\mathrm{CuK}_{\alpha}$ beam of radiation having wavelength $1.5406 \mathrm{~A}^{0}$. The crystalline phase of four AZTC NCs was compared with standard JCPDS card file No. 36-1451. Average particle size was calculated using the Scherrer Eq. (1) [12]:

$$
d=\frac{K \times \lambda}{\beta \times \cos \theta}
$$

Here, $d$ represents average particle size, $\lambda$ represents the wavelength of incident radiation, $\beta$ represents full angular width at half of maximum intensity diffraction peak, $K$ represents a constant known as Scherrer's constant and whose value is 0.94 and $\theta$ represent the angle of diffraction in the X-ray diffraction pattern. Fig. 6 shows FE-SEM images of alumina $\left(\mathrm{Al}_{2} \mathrm{O}_{3}\right)$, zinc oxide $(\mathrm{ZnO})$, titanium dioxide $\left(\mathrm{TiO}_{2}\right)$, and copper oxide $(\mathrm{CuO}) \mathrm{NCs}$.

\subsection{Computational study}

The theoretical study of synthesized metal oxide NPs was carried out by Gaussian09 and Material Studio 2017, USA software. The electronic and optical properties were studied by geometry optimization, energy, energy density, frequency, and orbital studies by DMol3, CASTEP, Forcite, Reflex, and VAMP modules. Fig. 7 shows DMol3 density of states (DOS), Forcite radial distribution function (RDF), Forcite X-ray intensity versus $2 \theta$ (XRD), Forcite X-ray intensity versus scattering vector, full width at half maxima (FWHM) versus $2 \theta$, CASTEP band structure, CASTEP density of states (DOS), and 3D molecular crystal structure depicting reciprocal lattice and Brillouin zone paths of $\mathrm{Al}_{2} \mathrm{O}_{3}$ obtained from Materials Studio 2017 software. Fig. 8 shows CASTEP band structure, CASTEP density of states (DOS), Forcite X-ray intensity versus $2 \theta$ (XRD), Forcite X-ray intensity versus scattering vector, Forcite geometry optimization for energy (GO), Forcite radial distribution function (RDF), XRD, Full width at half maxima (FWHM) versus $2 \theta$, the spatial distribution of atoms and $3 \mathrm{D}$ molecular structure showing reciprocal lattice and Brillouin zone paths of CuO nanoparticles. Fig. 9 shows CASTEP band structure, DMol3 DOS, Forcite concentration profile, Forcite radial distribution function (RDF), Forcite X-ray intensity versus scattering vector, XRD, Full width at half maxima (FWHM) versus 2 $\theta$, CASTEP optical properties, 3D crystal structure, spatial distribution of atoms, and 3D molecular structure showing reciprocal lattice and Brillouin zone paths of $\mathrm{TiO}_{2}$ nanoparticles. Fig. 10 shows CASTEP band structure, CASTEP DOS, Forcite concentration profile, CASTEP optimization convergence, Forcite radial distribution function (RDF), Forcite X-ray intensity versus scattering vector, XRD, Full width at half maxima (FWHM) versus $2 \theta$, 3D molecular plane, 3D molecular crystal structure showing reciprocal lattice and Brillouin zone paths of $\mathrm{ZnO}$ nanoparticles. 
The density of states (DOS) plots give a quick qualitative picture of the electronic structure of NPs and can be related directly to experimental spectroscopic results. The density of states for a given band $\mathrm{n}, N_{n}(E)$ was calculated by using Eq. (2).

$$
N_{n}(E)=\int \frac{d k}{4 \pi^{3}} \delta\left(E-E_{n}(k)\right)
$$

Here $E_{n}(k)$ represents the dispersion of a given band and integral was determined over the Brillouin zone. The DOS represents the number of allowed wave vectors in the nth band in the energy range $E$ to $(E+d E)$. The total DOS, $N(E)$ was obtained by summation over all bands. The DOS was also helpful to understand the changes in the electronic structure of NPs caused by external environmental factors.

The band structure plot shows how electronic energies depend on the $k$-vector, along with high symmetry directions in the Brillouin zone. The band structure was helpful in the qualitative analysis of the electronic structure of NPs. Band structure also helps in explaining the anisotropy of the optical properties. The optical energy band gap (CASTEP) was calculated from the energy difference between two states at high symmetry points.

\section{Results and discussion}

Figs. 1 and 2 show the optical band of four series of IMCs and NCs obtained from the UV-visible spectroscopy technique. Fig. 3 shows FT-IR absorption spectra of four series of NCs. The absorption peak at $1374 \mathrm{~cm}^{-1}$ in NC-1 may be due to $\mathrm{Zn}-\mathrm{O}$ and absorption peaks at 445 to $550 \mathrm{~cm}^{-1}$ are due to $\mathrm{Ni}-\mathrm{O}$ [13]. A small band at $950 \mathrm{~cm}^{-1}$ in the fingerprint region of NC-1 corresponds to Al-O. Two small peaks at 635.8 and $690.4 \mathrm{~cm}^{-1}$ in the fingerprint region of $\mathrm{NC}-1$ corresponds to $\mathrm{Cu}-\mathrm{O}$. The absence of any absorption peak in the functional group region shows the purity of NC-1. A broad peak at $3360 \mathrm{~cm}^{-1}$ in the NC-2 may be due to moisture present as an impurity. The absorption peak at $1350 \mathrm{~cm}^{-1}$ in NC-2 may be due to ZnO. The absorption peak at $1374 \mathrm{~cm}^{-1}$ in NC-3 is due to Zn-O in NCs. The peaks corresponding to $\mathrm{NiO}$ are absent in the FTIR spectrum of $\mathrm{NC}-3$. The peaks at 633 and $658 \mathrm{~cm}^{-1}$ are due to $\mathrm{Cu}-\mathrm{O}$ stretching vibrations in NC-3. The absorption peak at $1374 \mathrm{~cm}^{-1}$ in NC-4 may be due to $\mathrm{Zn}-\mathrm{O}$ and absorption peaks at 445 to $550 \mathrm{~cm}^{-1}$ are due to Ni-O stretching vibration. A small peak at $3400 \mathrm{~cm}^{-1}$ in NC-4 may be due to moisture present as an impurity. In all the four IR spectra, the functional group region is almost transparent. This shows the purity of all the four synthesized NCs (Fig. 3).

The average particle size obtained for four series of NCs was found to be in the range of 80-100 nm. "It is very difficult to explain the DC electrical conductivity of NCs only based on the X-ray diffraction pattern as it depends upon the number of factors like order of crystallinity, amorphous or crystalline character, presence of defects in crystal structures, presence of dopants, impurities or vacancies or holes in nano-crystalline phase structure" [14]. It was observed from the X-ray diffraction pattern of NC-2 and NC-3 that the 1-2-3 oxide layered structure is responsible for high conductivity which is due to conducting oxide layer of $\mathrm{CuO}$ act as a hole and alumina and zinc oxide act as charge reservoir (electrons) [15]. A clear shift in diffraction pattern peaks towards higher angles was observed in the case of AZTC NCs (Fig. 5). Characteristics ZnO peaks were observed at 23 (100), 27 (002), and 41 ${ }^{\circ}$ (101) corresponding to the Wurtzite structure of $\mathrm{ZnO}$ [16]. Ionic radius and the metal-metal bond length was observed by using Athena software [17]. The ionic radius of $\mathrm{Zn}^{2+}$ and $\mathrm{Ni}^{2+}$ ions was found out to be 0.60 and $0.55 \mathrm{~A}^{0}$, respectively. Characteristics diffraction peaks in Fig. 4 at 15, 20, 50, and $58^{\circ}$ correspond to metal-metal peaks of $\mathrm{Ni}-\mathrm{Al}$ [18]. Diffraction peaks at 
22, 26, 34, and $54^{\circ}$ correspond to Ti-Al metallic bond due to the formation of $\mathrm{TiAl}_{3}, \mathrm{TiAl}_{2}$, and TiAl IMC [19]. The formation of $\mathrm{TiAl}_{3}$ intermetallic compound is further confirmed by the change in enthalpy value $(\Delta H=-146.44$ $\mathrm{kJ} / \mathrm{mol}$ ) by DSC technique [20]. Nickel and zinc are said to be siderophiles. Copper and zinc are termed chalcophile. Copper and zinc are present adjacent to each other in the period and show almost identical chemical properties like ionic and atomic radii, electrode potential, atomic weight, etc. Due to this, $\mathrm{Cu}$ and $\mathrm{Zn}$ form sulfides, carbonates, oxides, and $\mathrm{Zn}-\mathrm{Cu}$ IMCs [21]. In absence of elemental sulfur, $\mathrm{Cu}-\mathrm{Zn}$ IMCs are formed which is confirmed by peaks at 21 (100), 25 (110), and $39^{\circ}$ (011) in AZTC NCs 2 and 4 (Fig. 5) [22]. After the sintering process at $600^{\circ} \mathrm{C}$, no significant changes in shape (deformation or contraction) were observed for AZTC IMCs confirmed by XRD and FE-SEM techniques.

The NC-1 and NC-3 show some puffy ball-like structures whereas NC-2 and NC-4 show the more compact, spherical, and uniform ball-like structures of NCs (Fig. 6). An increase in the concentration of copper and aluminum in AZTC NCs results in swelling (puffy balls) and an increase in the concentration of nickel and zinc results in compactness in AZTC NCs. Uniform mixing of all the four metal oxides in NCs was observed during their sol-gel synthesis.

Table 5 shows different Holm factor and fit parameters obtained from the Holm equation [23] under different heat 196 treatment temperatures for all four series of NCs, respectively. Holm factor, $\beta$, is termed as plastic contact whose value was found to be 0.33 at $400{ }^{\circ} \mathrm{C}$ and 0.51 at $100{ }^{\circ} \mathrm{C}$. Holm factor of 0.51 represents elastic contact between the nanoparticles of AZTC NC-3 [24]. An increase in heat treatment temperature (100 to $\left.400{ }^{\circ} \mathrm{C}\right)$ leads to an increase in plastic contact between nanoparticles which increases electrical conductivity. The same was confirmed from the FESEM image (Fig. 6) i.e., puffy balls (Holm factor, $\beta,=0.5$ ) and compacted regular spherical shapes (Holm factor, $\beta$, $=0.33)$ of AZTC NCs.

The theoretical study (computational) was performed to investigate band structure, optical bad gap, the density of states, XRD (theoretical), FWHM versus $2 \theta$, optical properties, radial distribution function (RDF), reciprocal lattice, and Brillouin zone paths for $\mathrm{Al}_{2} \mathrm{O}_{3}, \mathrm{CuO}$ (anatase), $\mathrm{TiO}_{2}$ and $\mathrm{ZnO}$ NPs, respectively (Figs. 7-10). Band structure charts show how electronic energies depend on the k-vector, along with high symmetry directions in the Brillouin zone. Band structure of $\mathrm{Al}_{2} \mathrm{O}_{3}, \mathrm{CuO}$ (anatase), $\mathrm{TiO}_{2}$, and $\mathrm{ZnO}$ NPs also helps in qualitative analysis of the electronic structure and optical properties. In Fig. 7(G), the electronic states with different spins of $\mathrm{Al}_{2} \mathrm{O}_{3}$ NPs are presented using different colors, and Fermi levels are shown by the dashed line. All the energies are related to the Fermi level. The labels along the $\mathrm{X}$-axis of the band structure graph corresponds to a standard definition of high symmetry points for the given lattice type. The $\Gamma$ symmetry point is denoted by $\mathrm{G}$. The maximum band gap observed in the case of $\mathrm{Al}_{2} \mathrm{O}_{3} \mathrm{NPs}_{\text {sas }}$ $5.538 \mathrm{eV}$ at $\mathrm{F}$ and $\mathrm{Z}$ symmetry points. In Fig. 7(H), CASTEP density of states (DOS) represent Gaussian smearing of energy levels of each and followed by histogram for different k-points. In the CASTEP module, linear interpolation in parallelepipeds formed by k- points of Monkhorst-Pack set followed by histogram sampling of resultant set of band energies was used. The DOS provides characteristics information such as the width of the valence band, energy gap, by the Forcite module for finding the probability function, $\mathrm{g}(\mathrm{r})$ between $\mathrm{Al}$ and $\mathrm{O}$ atoms for the distance $(\mathrm{r})$ in a random 218 atomic scattering procedure. Fig. 7(B) shows RDF between $\mathrm{Al}$ and $\mathrm{O}$ atoms. The maximum distance selected was 20 
$\mathrm{A}^{0}$ and the interval was $0.01 \mathrm{~A}^{0}$. The $\mathrm{g}(\mathrm{r})$ was found to have a maximum up to $9 \mathrm{~A}^{0}$ after that it was almost constant. Fig. 7(D) shows the Forcite module for X-ray intensity versus scattering vector, $Q$ and it was observed that intensity of X-ray first decreases linearly and then exponentially with scattering vector. The full width at half of the maxima (FWHM) was found to increase linearly with an increase in scattering angle (Fig. 7, E). The highest intensity peak in theoretical XRD spectra was observed at $2 \theta=35$ for $\mathrm{Al}_{2} \mathrm{O}_{3}$ NPs (Fig. 7 (F)).

Fig. 8(A) shows the CASTEP band structure for CuO NPs with almost zero bandgaps near G symmetry point. Fig. 8(B) shows DOS for CuO NPs. The intensity of the wave vector was found to be highest in the negative region of energy. Fig. 8(D) shows the Forcite module for X-ray intensity versus scattering vector, Q and it was observed that intensity of X-ray first decreases linearly and then exponentially with an increase in scattering vector. The radial distribution function (RDF) was carried out by the Forcite module for finding the probability function, $g(r)$ between $\mathrm{Cu}$ and $\mathrm{O}$ atoms for the distance $(\mathrm{r})$ in a random atomic scattering procedure. Fig. 8(F) shows RDF between $\mathrm{Cu}$ and $\mathrm{O}$ atoms. The maximum distance selected was $20 \mathrm{~A}^{0}$ and the interval was $0.01 \mathrm{~A}^{0}$. The $\mathrm{g}(\mathrm{r})$ was found to have a maximum up to $12 \mathrm{~A}^{0}$ after that it was almost constant. The highest intensity peak in theoretical XRD spectra was observed at $2 \theta=35.8$ and 39 for $\mathrm{CuO}$ NPs (Fig. 8, C). Fig. 8(E) shows the variation in $\mathrm{CuO}$ enthalpy per step Forcite module of geometry optimization performed to a maximum of 21 steps. It was observed that the enthalpy of $\mathrm{CuO}$ decreases from 608 to $600 \mathrm{kcal} / \mathrm{mol}$ after 4 step optimization and then remains almost constant.

Fig. 9(A) shows the CASTEP band structure for $\mathrm{TiO}_{2} \mathrm{NPs}$ with a constant bandgap of $2.121 \mathrm{eV}$ at $\mathrm{G}, \mathrm{X}, \mathrm{P}$, and $\mathrm{N}$ symmetry points. From the bandgap study, it was observed that the electrical conductivity of $\mathrm{TiO}_{2}$ was higher than $\mathrm{Al}_{2} \mathrm{O}_{3}$ but lesser than CuO NPs. Fig. 9(B) shows DMol3 DOS for $\mathrm{TiO}_{2}$ NPs. The intensity of the wave vector was found to be higher in the positive region of energy. The relative concentration of Ti atoms (Fig. 9 (C) at different surface was found in the following order: $\mathrm{Ti}(001)>\mathrm{Ti}(010)>\mathrm{Ti}(100)$. Fig. 9(D) shows RDF between $\mathrm{Ti}$ and $\mathrm{O}$ atoms. The maximum distance selected was $20 \mathrm{~A}^{0}$ and the interval was $0.01 \mathrm{~A}^{0}$. The $\mathrm{g}(\mathrm{r})$ was found to have a maximum up to $9 \mathrm{~A}^{0}$ after that it was almost constant. Fig. 9(E) shows the Forcite module for X-ray intensity versus scattering vector, $\mathrm{Q}$ and it was observed that intensity of $\mathrm{X}$-ray first decreases linearly and then exponentially with an increase in scattering vector. The highest intensity peak in theoretical XRD spectra of $\mathrm{TiO}_{2}$ (anatase) $\mathrm{NPs}$ was observed at $2 \theta$ $=25$ (Fig. 8, F). The full width at half of the maxima (FWHM) was found to increase linearly with an increase in scattering angle (Fig. 9, G). Fig. 9(H) shows CASTEP optical properties of $\mathrm{TiO}_{2} \mathrm{NPs}$ performed at scissors operator $=0 \mathrm{eV}$, smearing at $0.05 \mathrm{eV}$ and polarization direction (100). The intensity of reflectivity was found to decrease with an increase in frequency and becomes zero at a frequency of $60 \mathrm{eV}$.

Fig. 10(A) shows the CASTEP band structure for ZnO NPs with an average bandgap of $0.765 \mathrm{eV}$ and zero at $\mathrm{G}$ and L symmetry points. Hence, from the bandgap study, it was concluded that the order of electrical conductivity of four $\mathrm{NPs}$ is $\mathrm{CuO}>\mathrm{ZnO}>\mathrm{TiO}_{2}>\mathrm{Al}_{2} \mathrm{O}_{3}$. Fig. 10(B) shows CASTEP DOS for ZnO NPs. The intensity of the wave vector was found to be higher in the negative region of energy. The relative concentration of $\mathrm{Zn}$ atoms (Fig. 10 (C) at different surface was found in the following order: Zn (010) $>$ Zn (001) $>$ Zn (100) $>$ Zn (001). Fig. 10(E) shows RDF between $\mathrm{Zn}$ and $\mathrm{O}$ atoms. The maximum distance selected was $20 \mathrm{~A}^{0}$ and the interval was $0.01 \mathrm{~A}^{0}$. The $\mathrm{g}(\mathrm{r})$ was found to have a maximum up to $12 \mathrm{~A}^{0}$ after that it was almost constant. Fig. 10(E) shows the Forcite module for X-ray intensity 
versus scattering vector, $\mathrm{Q}$ and it was observed that intensity of X-ray first decreases linearly and then exponentially with an increase in scattering vector. The highest intensity peak in theoretical XRD spectra of ZnO NPs was observed at $2 \theta=36.4$ (Fig. 10, G). The full width at half of the maxima (FWHM) was found to increase linearly with an increase in scattering angle (Fig. 10, H).

The electrical conductivity of $\mathrm{Al}_{2} \mathrm{O}_{3}, \mathrm{ZnO}, \mathrm{TiO}_{2}$, and $\mathrm{CuO} \mathrm{NCs}$ increases with a decrease in temperature i.e., $25^{\circ} \mathrm{C}$ to $-70^{\circ} \mathrm{C}$ at normal atmospheric pressure (Fig. 11). The highest electrical conductivity was observed for NC-2 followed by $\mathrm{NC}-3$ and then $\mathrm{NC}-4$ and then $\mathrm{NC}-1$ at $-70^{\circ} \mathrm{C}$. Metal $\mathrm{NC}-2$ has the highest ratio of $\mathrm{Al}_{2} \mathrm{O}_{3}$ followed by $\mathrm{CuO}$ and then $\mathrm{ZnO}$ and $\mathrm{NiO}_{2}$. The high order of conductivity observed in the case of $\mathrm{NC}-2$ was due to the increase in electrical contact between $\mathrm{Al}_{2} \mathrm{O}_{3}$ (charge reservoir) and $\mathrm{CuO}$ (acting as a hole) with a decrease in temperature.

The electrical conductivity of $\mathrm{Al}_{2} \mathrm{O}_{3}, \mathrm{ZnO}, \mathrm{TiO}_{2}$, and $\mathrm{CuO}$ NCs was also found to increase with an increase in heat treatment temperature i.e., 100 to $400^{\circ} \mathrm{C}$ at normal atmospheric pressure (Fig. 12). Electrical conductivity was found to be maximum for $\mathrm{NC} 3$ followed by $\mathrm{NC} 2$ and then $\mathrm{NC} 4$ and $\mathrm{NC} 1$ at $400^{\circ} \mathrm{C}$. This increase in electrical conductivity with the increase in heat treatment temperature (Table 5) was due to a decrease in the Holm factor, $\beta$, termed as plastic contact whose value was observed to be 0.33 at $400^{\circ} \mathrm{C}$ and 0.51 at $100^{\circ} \mathrm{C}$. Holm factor of 0.51 represents elastic contact between the nanoparticles of metal NC-3 [24]. An increase in heat treatment temperature leads to an increase in plastic contact between nanoparticles which increases electrical conductivity.

The absorption coefficient $(\alpha)$ was obtained from the value of maximum absorption, $A_{\max }$, obtained from UV-visible absorption spectra, by Eq. (3) [25].

Here, $A_{\max }$ is maximum absorption and $t$ is the thickness or path length. The value of band-gap, $\left(E_{g}\right)$, was calculated 280 by using Tauc relation, Eq. (4) [26].

The optical bandgap $\left(E_{g}\right)$, calculated from Tauc relation by the use of UV visible spectroscopy for four different IMCs and their corresponding NC and are shown in Figs. 1 and 2, respectively. The optical band gap for four IMCs was found approximately equal to 2 . The optical band gap was found to be minimum for IMC-1 and maximum for IMC2. The optical band gap $\left(E_{g}\right)$, for four series of metal NCs were found to be less than 1 (Fig. 2). The optical band gap was found to be minimum for metal NC-3 and maximum for metal NC-1 but still less than all the four IMCs.

The effect of the addition of ferromagnetic Hematite, $\alpha-\mathrm{Fe}_{2} \mathrm{O}_{3}$ in the different ratio $(0.5 \mathrm{M})$ to form Ferrite/ metal NCs were also investigated. Table 6 shows the different concentrations of Hematite used in the four series of metal NCs. The effect of the addition of coinage metal $(\mathrm{Cu}$ and $\mathrm{Ag})$ in the different ratios $(0.5 \mathrm{M})$ to form four series of coinage metal NC (CM) are shown in Table 7. Table 8 shows the DC electrical conductivity measured by multimeter, LCR meter, and optical bandgap calculated by using UV-visible spectroscopy technique for four different metal NCs having the different composition of Hematite $\left(\alpha-\mathrm{Fe}_{2} \mathrm{O}_{3}\right)$. Table 9 shows DC electrical conductivity measured by multimeter, LCR meter, and optical bandgap calculated by using UV-visible spectroscopy technique for four different metal NCs having the different composition of coinage metals i.e., copper and silver. From Tables 8 and 
9, it was concluded that the addition of Hematite and coinage metals does not increase the electrical conductivity of

297 NCs to a very significant extent. But the addition of coinage metal to the NCs increases the cost of NCs to a significant 298 effect.

\section{Conclusions}

300 Four series of IMCs and $\mathrm{NCs}$ of $\mathrm{Al}_{2} \mathrm{O}_{3}, \mathrm{ZnO}, \mathrm{TiO}_{2}$, and $\mathrm{CuO}$ (anatase) were synthesized by self-propagating high301 temperature reactive synthesis and sol-gel technique (ex-situ), respectively. DC electrical conductivity of NCs was 302 compared with their IMCs. Characterization of IMCs and NCs was carried out by UV-visible, FTIR, FE-SEM, and 303 XRD techniques. The theoretical (computational) study was carried out to study the electrical and optical properties 304 of synthesized four metal NPs. The average particle size observed from the X-ray diffraction study for NCs was found 305 to be $80-100 \mathrm{~nm}$. The electrical properties of IMCs and corresponding NCs were found to be different. The order of 306 electrical conductivity of four NPs was found in the following order: $\mathrm{CuO}>\mathrm{ZnO}>\mathrm{TiO}_{2}>\mathrm{Al}_{2} \mathrm{O}_{3}$. In IMCs, electrical 307 conductivity increases with an increase in the concentration of Ti and Al but in NCs electrical conductivity increases 308 with an increase in the concentration of $\mathrm{Al}_{2} \mathrm{O}_{3}$ and $\mathrm{CuO}$. The layered structure of NCs was responsible for a high order 309 of conductivity in which conducting oxide layer of $\mathrm{CuO}$ (act as a hole) and $\mathrm{Al}_{2} \mathrm{O}_{3}$ and $\mathrm{ZnO}$ act as charge reservoir 310 (electrons). The electrical conductivity of metal oxide NCs increases with an increase in heat treatment temperature 311 (up to $400^{\circ} \mathrm{C}$ ) and also increases with a decrease in temperature $\left(-70^{\circ} \mathrm{C}\right)$. An increase in electrical conductivity with 312 heat treatment temperature was due to an increase in plastic content and a decrease in the Holm factor, $\beta$. The addition 313 of Hematite, $\alpha-\mathrm{Fe}_{2} \mathrm{O}_{3}$ (ferromagnetic), and the addition of coinage metals ( $\mathrm{Ag}$ and $\mathrm{Au}$ ) in NCs does not significantly 314 increase the electrical conductivity. The room temperature electrical conductivity of NCs was found to be higher than 315 IMCs. Hence, synthesized NCs can have a large number of potential applications in sophisticated electronic 316 appliances.

\section{Acknowledgments}

319 We are very grateful to the authorities of the Central University of Haryana, Mahendergarh for providing all types of 320 the research facility and infrastructure support for carrying out this research work.

\section{Conflict of Interest}

322 Authors have no conflict of interest with any agency or person or institute in publishing this paper. 


\section{References}

1. D. Dounghong, J. Ramsden, M. Gratzel, Dynamics of interfacial electron transfer processes in colloidal semiconductor systems. J. Am. Chem. Soc. 104, 2977-2985 (1982).

2. W. Mingwen, S. Lingdong, F. Xuefeng, L. Chunsheng, Y. Chunhua, Synthesis and optical properties of ZnS: Cu(II) nanoparticles. Solid State Comm. 115, 493-496 (2000).

3. C. S. Pathak, M. K. Mandal, V. Agarwal, Optical properties of undoped and cobalt doped ZnS nanophosphor. Mater. Sci. Semicond. Proc. 16(2), 467-471 (2013).

4. C. S. Pathak, M. K. Mandal, V. Agarwal, Synthesis and characterization of zinc sulfide nanoparticles prepared by mechanochemical route. Super lattices \& Microst. 58, 135-143 (2013).

5. C. S. Pathak, D. D. Mishra, V. Agarwal, M.K. Mandal, Blue light emission from barium doped ZnS nanoparticles. Ceramics Int. 38, 5497-5500 (2012).

6. C. S. Pathak, D. D. Mishra, V. Agarwal, M. K. Mandal, Optical properties of ZnS nanoparticles prepared by high energy ball milling. Mater. Sci. Semicond. Proc. 16(2), 525-529 (2013).

7. D.R. Penn, Wavenumber dependent dielectric function of semiconductors. Phys. Rev. 128(5), 2093 (1962).

8. S. Suresh, Review on the theoretical aspect of nonlinear optics. Intern. J. Phys. Sci. 8(21), 11211127 (2013).

9. A. Barroso-Bogeat, C. Fernandez-Gonalez, M. Alexandre-Franco, V. Gomez-Serrano, Activated carbon as a metal oxide support: a review, inactivated carbon: classifications, properties, and applications. (Nova Science Publishers, New York, 2011). pp. 67-85.

10. H. Kumar, R. Rani, Rahul, A. Yadav, Rajni, Synthesis, characterization and influence of reduced Graphene Oxide ( $\mathrm{rGO}$ ) on the performance of mixed metal oxide nanocomposite as optoelectronic material and corrosion inhibitor. Chemical Data Collection 29, 100527 (2020). https:// doi.org/10.1016/j.cdc.2020.100527

11. H. Kumar, A. Boora, A. Yadav, Rajni, Rahul, Polyaniline-metal oxide-nano-composite as a nano-electronics, optoelectronics, heat resistance, and anti-corrosive material. Results in Chem. 2, 100046 (2020). https://doi/10.1016/j.rechem.2020.100046

12. L. Wu, Y.S. Wu, W. Lu, Preparation of $\mathrm{ZnO}$ nanorods and optical characterization. Physica E. 28, 76 (2005).

13. J.I. Langford, A.J.C. Wilson, Scherrer after sixty years: A survey and some new results in the determination of crystallite size. J. Appl. Crystallogr. 11, 102-113 (1978).

14. J. M. Montes, F.G. Cuevas, J. Cintas, P. Urban, Electrical conductivity of metal powders under pressure. Appl. Phys. A: Mater Sci. Proc. 105, 935-947 (2011).

15. K.A. Müller, J.G. Bednorz, Possible high Tc superconductivity in the Ba-La-Cu-O system. Z Phys. B. 64(2), 189-193 (1986).

16. K. P. Shinde, R. C. Pawar, B.B. Sinha, H.S. Kim, S. S. Oh, K.C. Chung, Optical and magnetic 
properties of $\mathrm{Ni}$-doped $\mathrm{ZnO}$ planetary ball milled nanopowder synthesized by co-precipitation.

Ceramic Internat. 40, 16799-16804 (2014). http://dx.doi.org/10.1016\%2Fj.ceramint.2014.07.148

17. R. D. Shannon, Revised effective ionic radii and systematic studies of interatomic distances in halides and chalcogenides. Acta Crystallogr. Sect. A. 32(5), 751-767 (1976).

18. M.O. Rana, M.U. Islam, I. Ahmad, I. Abass, Proc. of International Symposium on advanced materials. Advanced Mat 21-23 ${ }^{\text {th }}$ Sept, Islamabad, Pakistan, 283 (1997).

19. J. Sienkiewicz, S. Kuroda, R.M. Molak, H. Murakami, H. Araki, S. Takamori, Fabrication of TiAl intermetallic phase by heat treatment of marm sprayed metal precursors. Intermetallics 49, 57-64 (2014).

20. W. Zhang, J. Xinyang, F. Peizhong, W. Ziahong, L. Zhangsheng, A. Farid, Highly porous open cellular TiA based intermetallics fabricated by the thermal explosion with space holder process. Intermetallics 68, 95-100 (2016).

21. L.J. Jun, M.A.O. Guang Jian, M.A. Xing Hua, L.B.G. YuQuian, L.G. Zhi, Discovery of Cu-Ni-SnFe intermetallic compounds and S-bearing alloys in the Zhaishang gold deposit, Southern Gansu Province and its geological significance. Sci. China Ser. D-earth Sci. 51(6), 769 (2008).

22. Y. Z. Xie, Z. Q. Hou, J.H. Xu, Discovery of $\mathrm{Cu}-\mathrm{Zn}, \mathrm{Cu}-\mathrm{Sn}$ intermetallic minerals and its significance for the genesis of the mianing-Dechang REE metallogenic Belt, Sichuan Province, China. Sci. China Ser. D-earth Sci. 49(6), 597 (2006).

23. R. Holm, H. Gaber, Electric contacts. Stockholm (1946).

24. R. Holm, E. Holm, Electric contacts: Theory and applications. (Springer-Verlag, Berlin, 1967).

25. H. Kumar, R. Rani, Structural and optical characterization of ZnO nanoparticles synthesized by microemulsion route. Int. Letters of Chem. Phys. \& Astronomy 14, 26-36 (2013).

26. N.F. Mott, E.A. Davies, Electronic Processes in Non-Crystalline Materials. (Clare don Press, Oxford, 1979). 
Figures

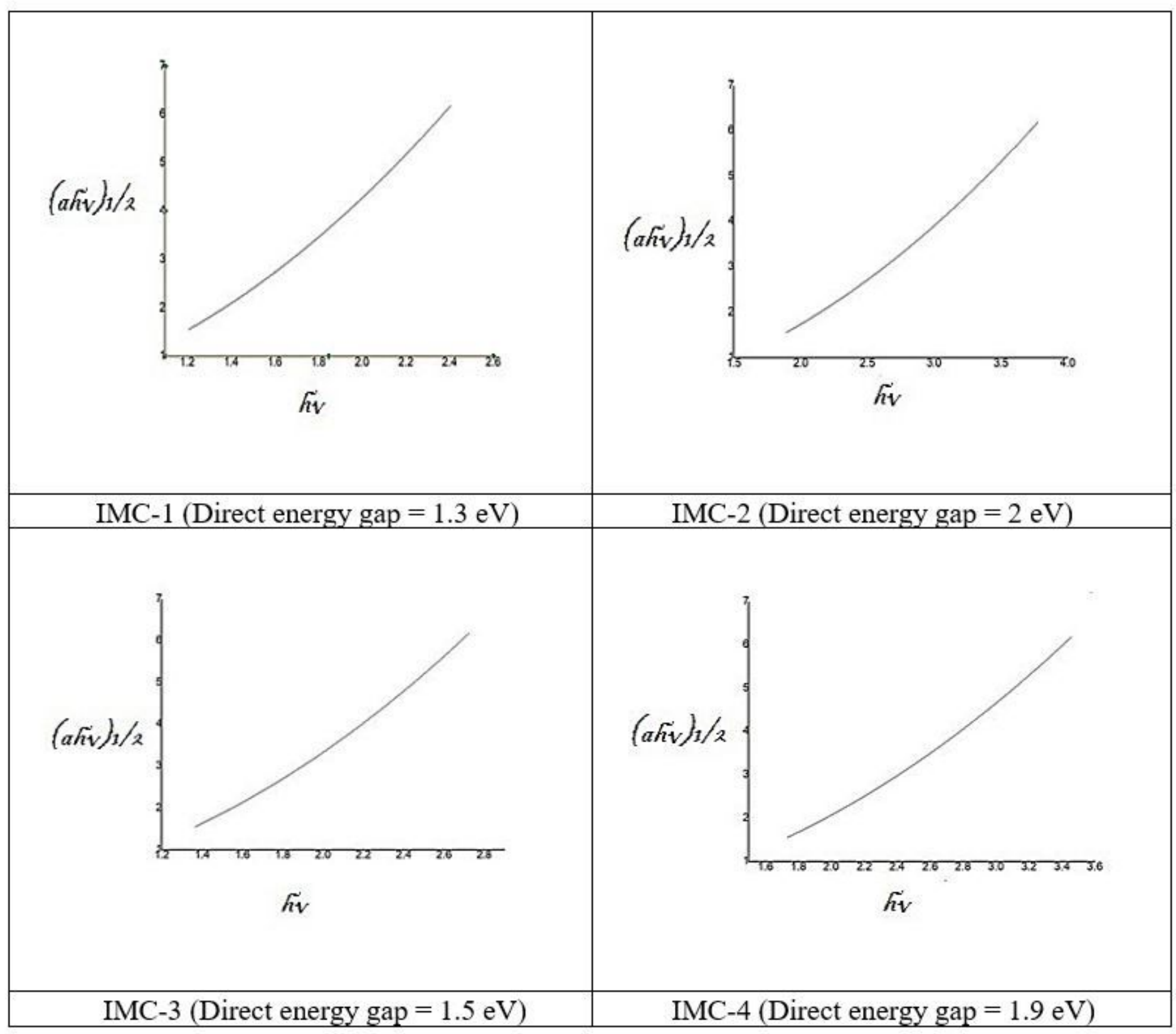

Figure 1

Optical band energy gap (eV) observed for four series of IMCs using Tauc relation calculated from absorption maxima observed from UV-visible spectroscopy 


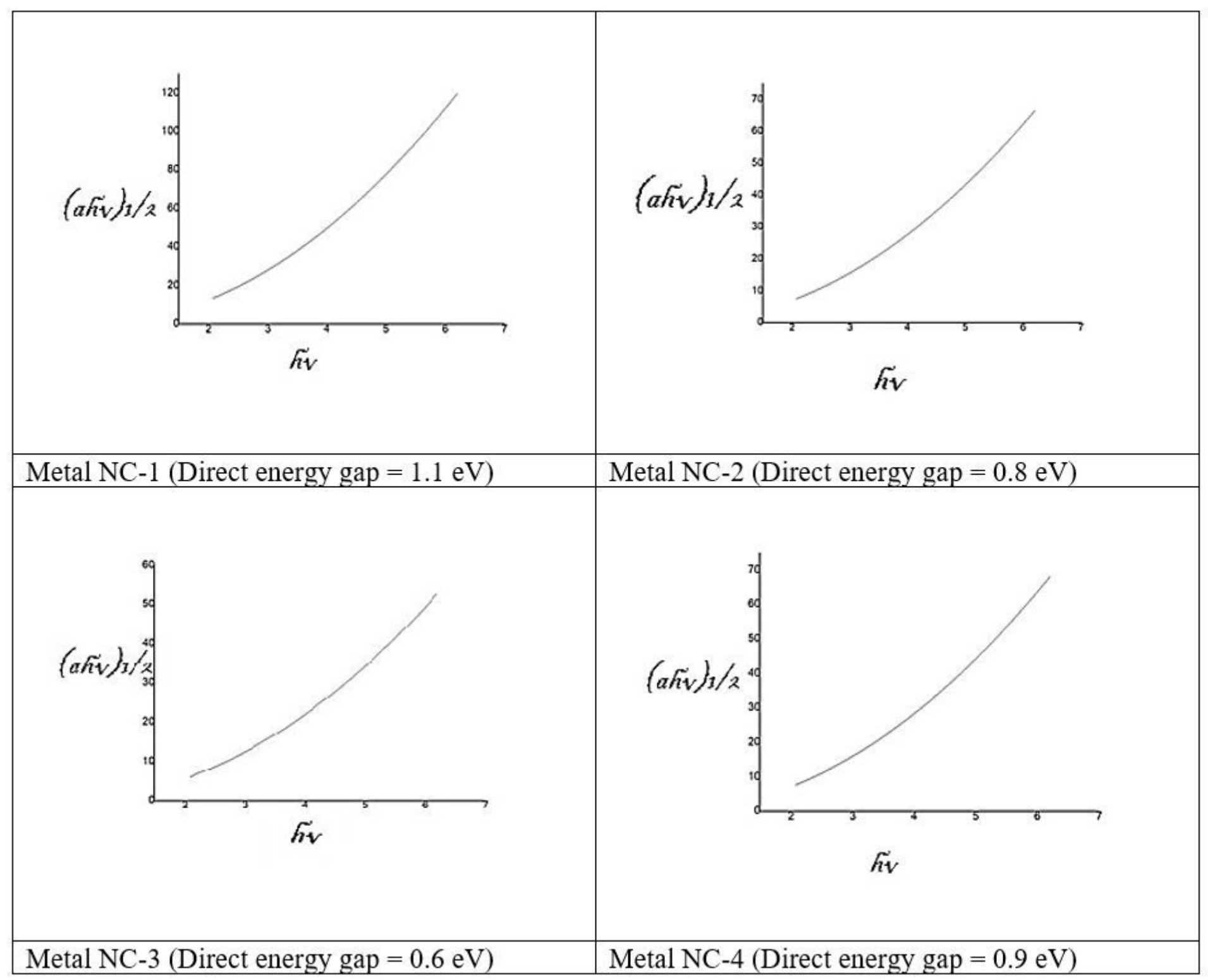

\section{Figure 2}

Optical energy band gap (eV) calculated from Tauc relation for four series of NCs by using absorption maxima, Amax., observed from UV-visible spectroscopy. 

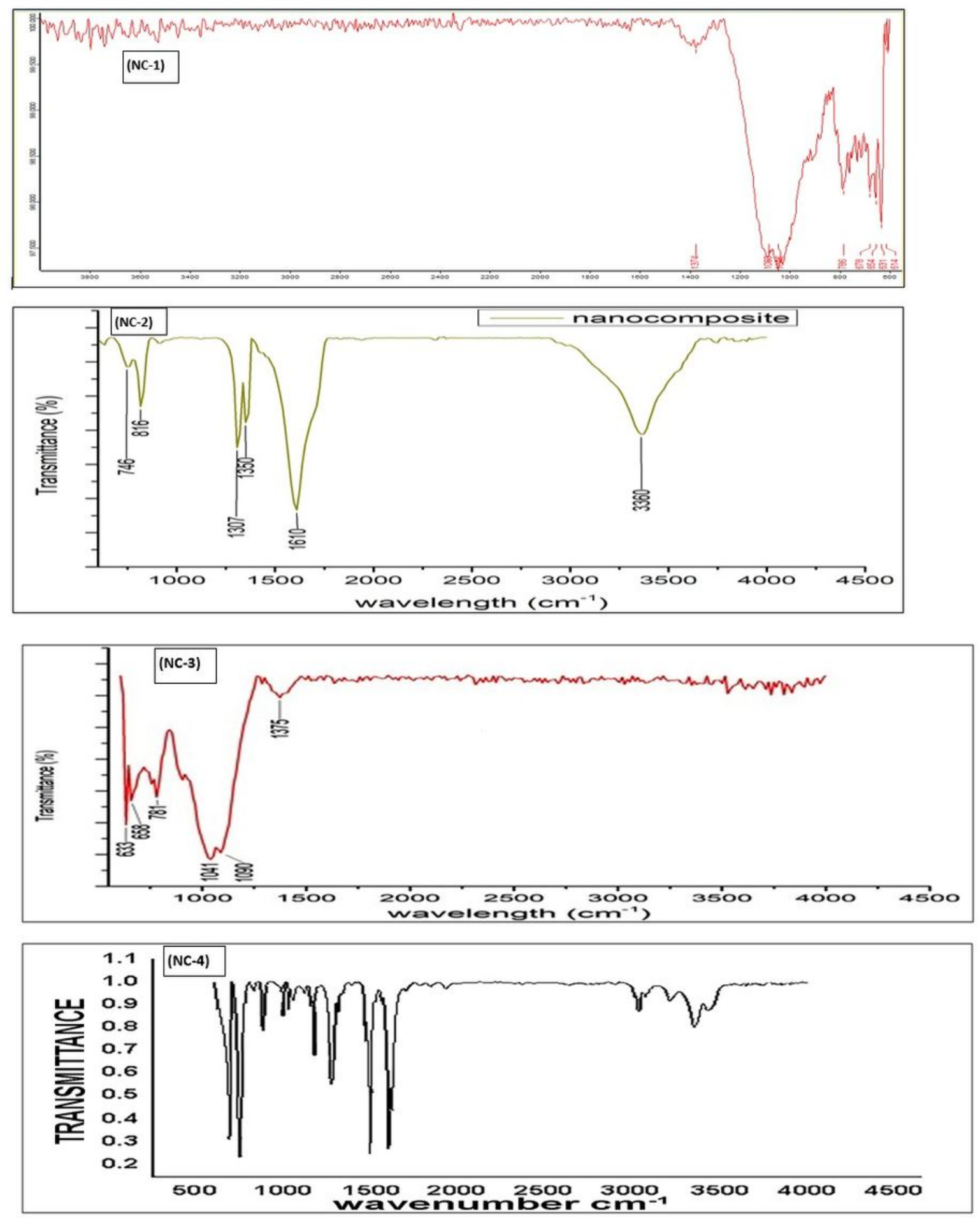

Figure 3

FTIR absorption spectra of four series of AZTC, NCs. 


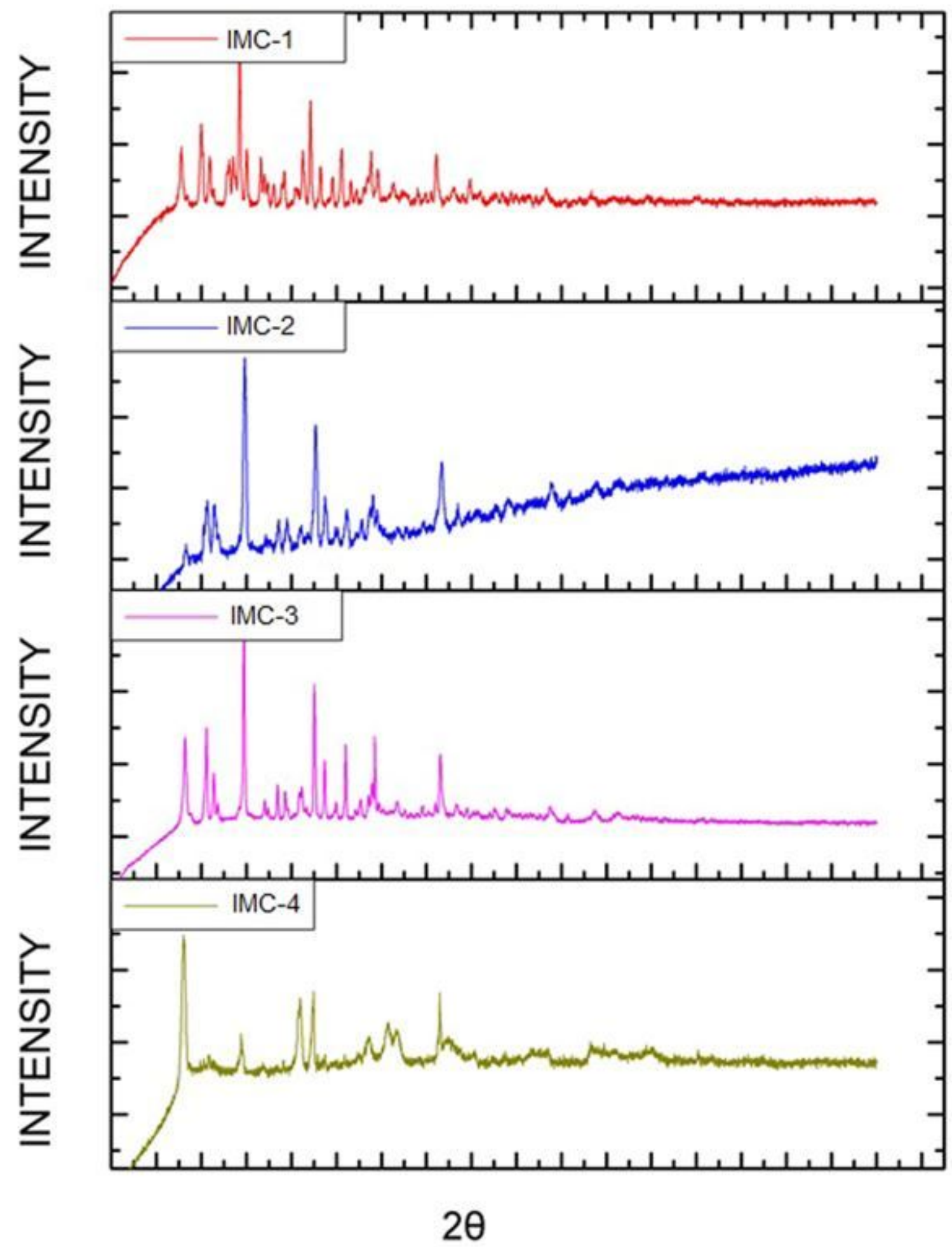

Figure 4

X-ray diffraction pattern of four series of Al203, CuO, TiO2 and ZnO IMCs. 


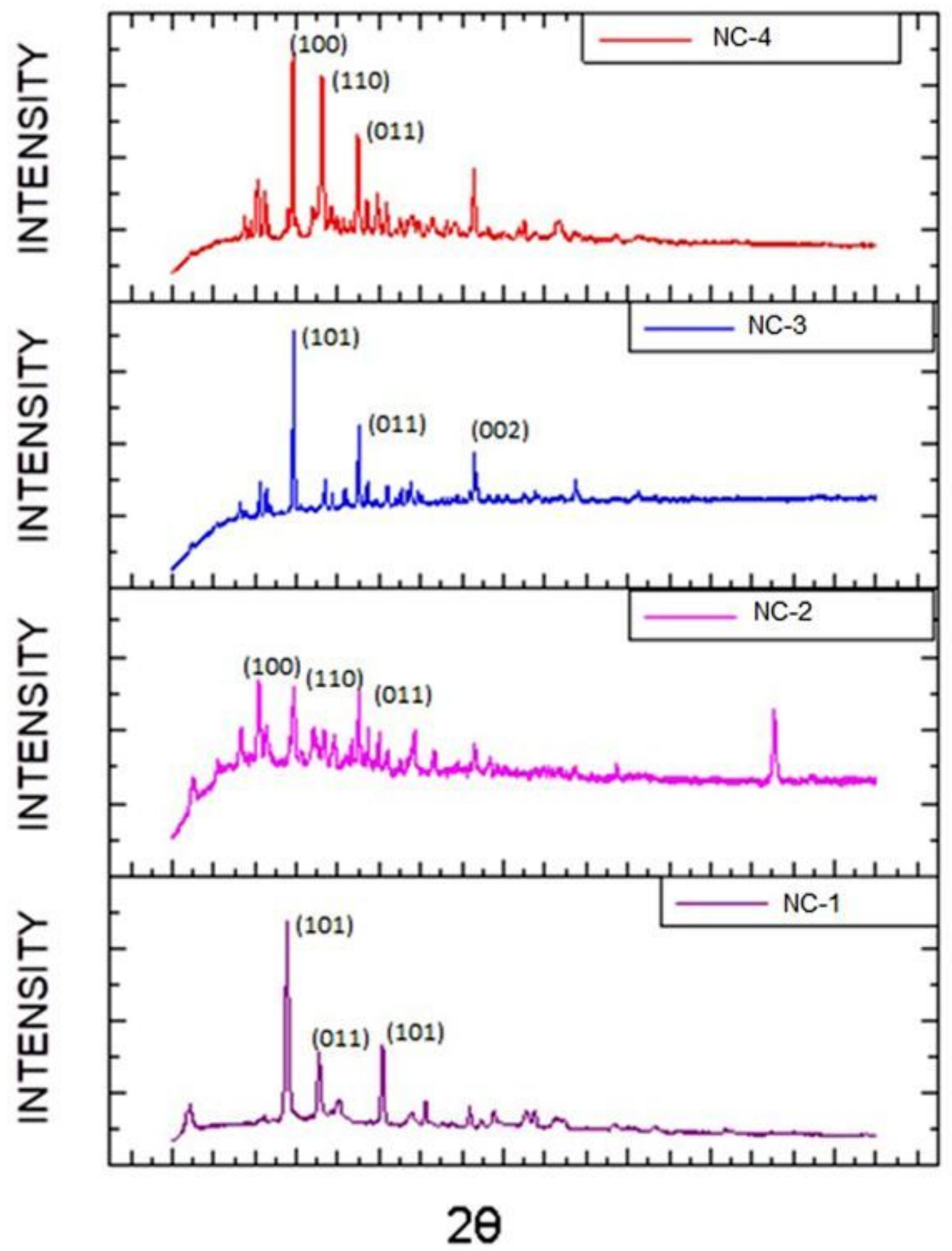

Figure 5

X-ray diffraction pattern of four series of $\mathrm{Al} 2 \mathrm{O} 3, \mathrm{CuO}, \mathrm{TiO} 2$ and $\mathrm{ZnO}$ NCs. 

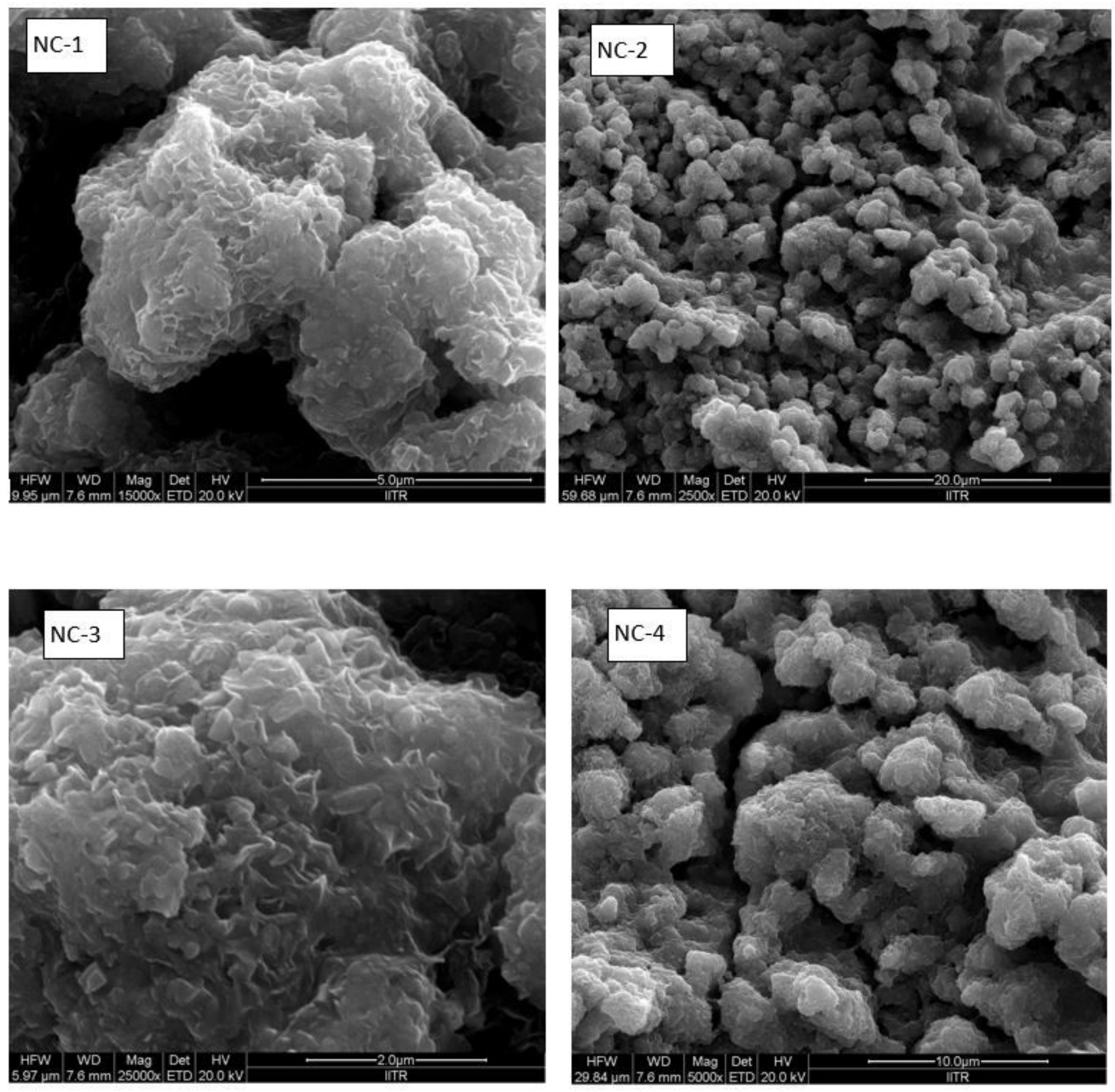

Figure 6

FE-SEM images of four Al2O3, CuO, TiO2 and ZnO NCs synthesized by Sol-gel technique. 

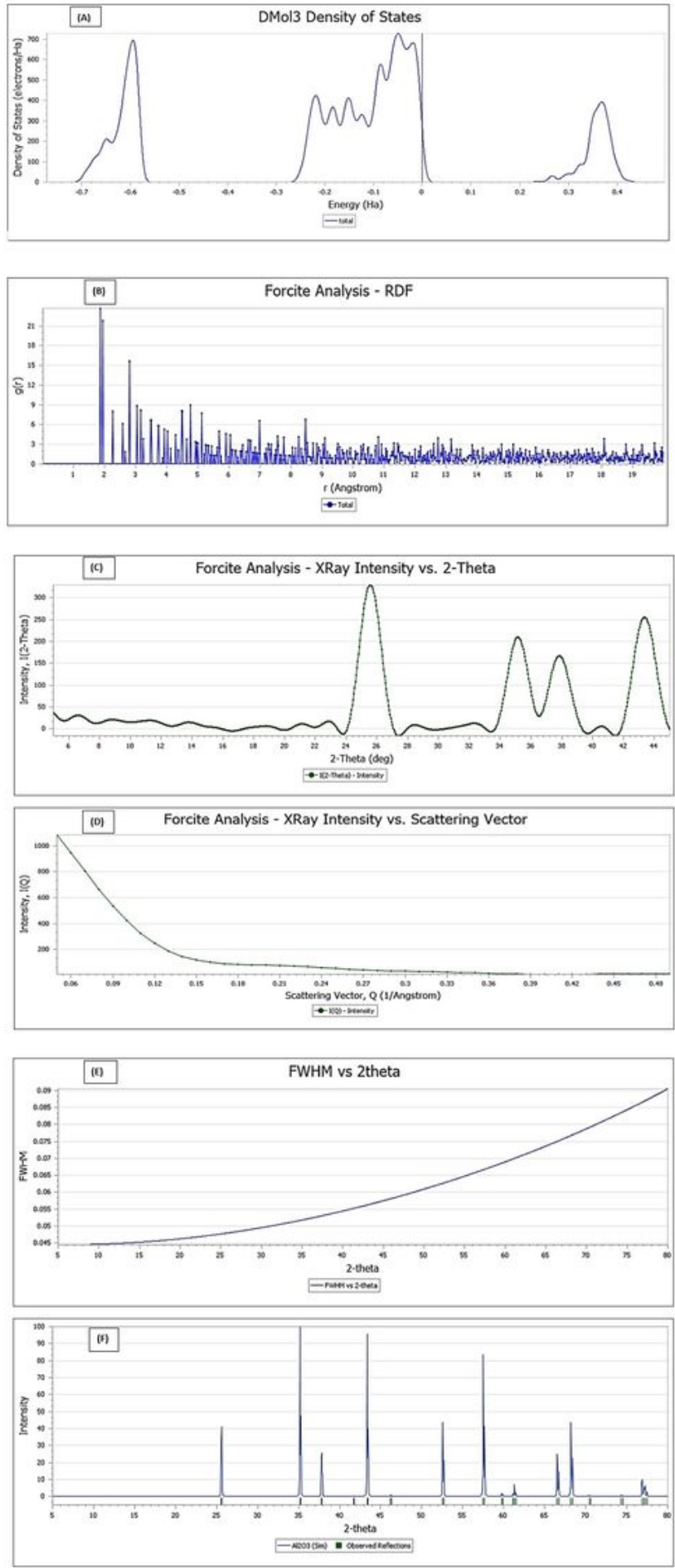
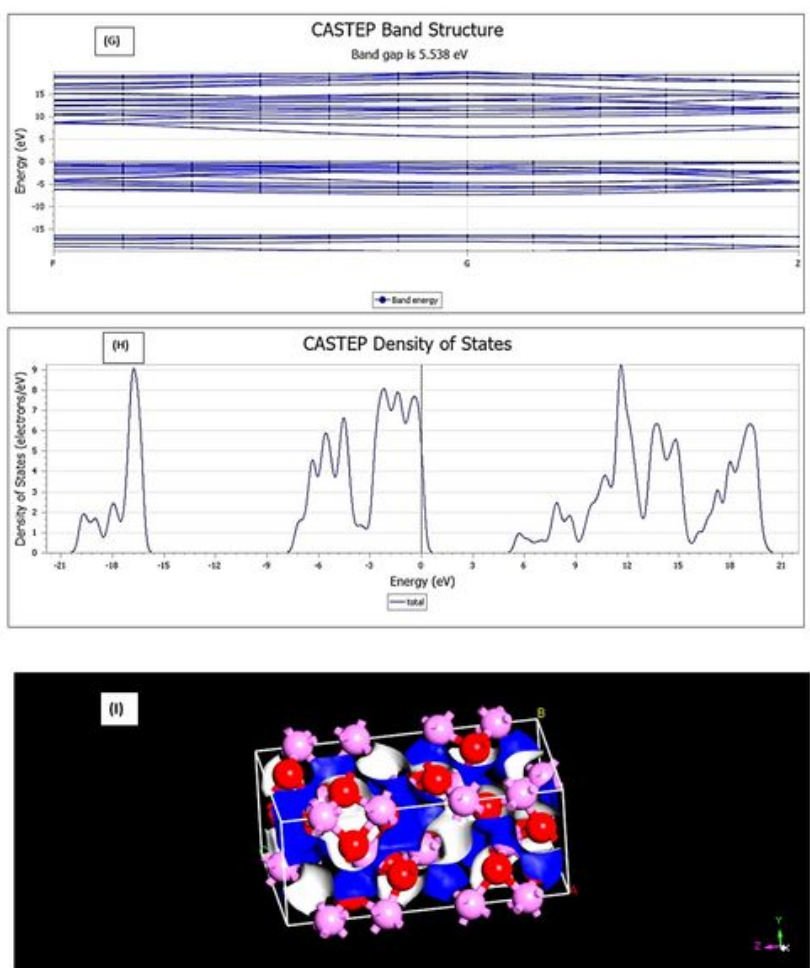

\section{Figure 7}

DMol3 Density of States (A), Forcite radial distribution function (B), Forcite X-ray intensity versus $2 \theta$ (C), Forcite X-ray intensity versus scattering vector (D), Full width at half maxima versus $2 \theta$ (E), CASTEP band structure $(G)$, CASTEP density of States $(H)$, and 3D molecular crystal structure showing reciprocal lattice and Brillouin zone paths of Al2O3 obtained from Materials Studio 2017 software. 

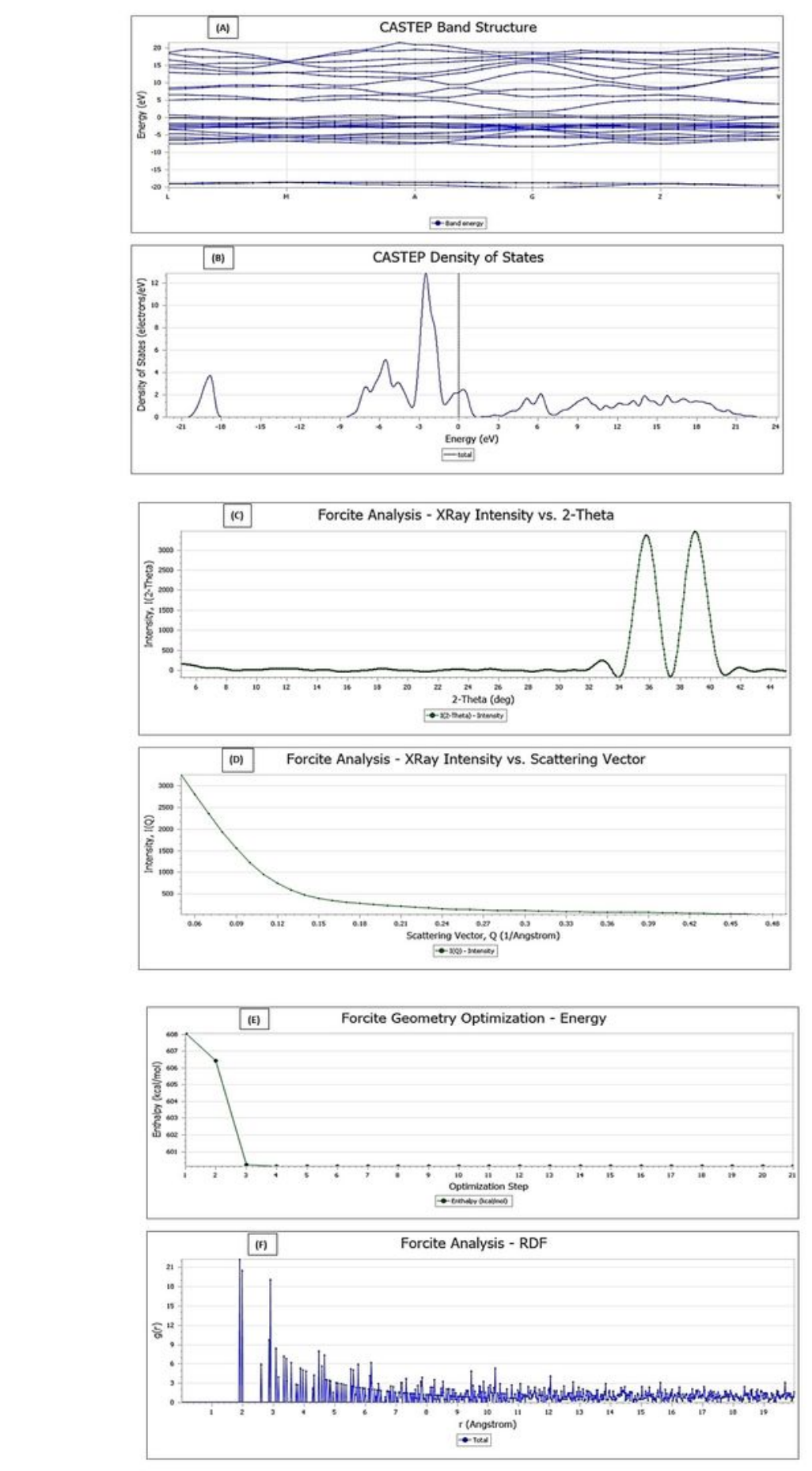
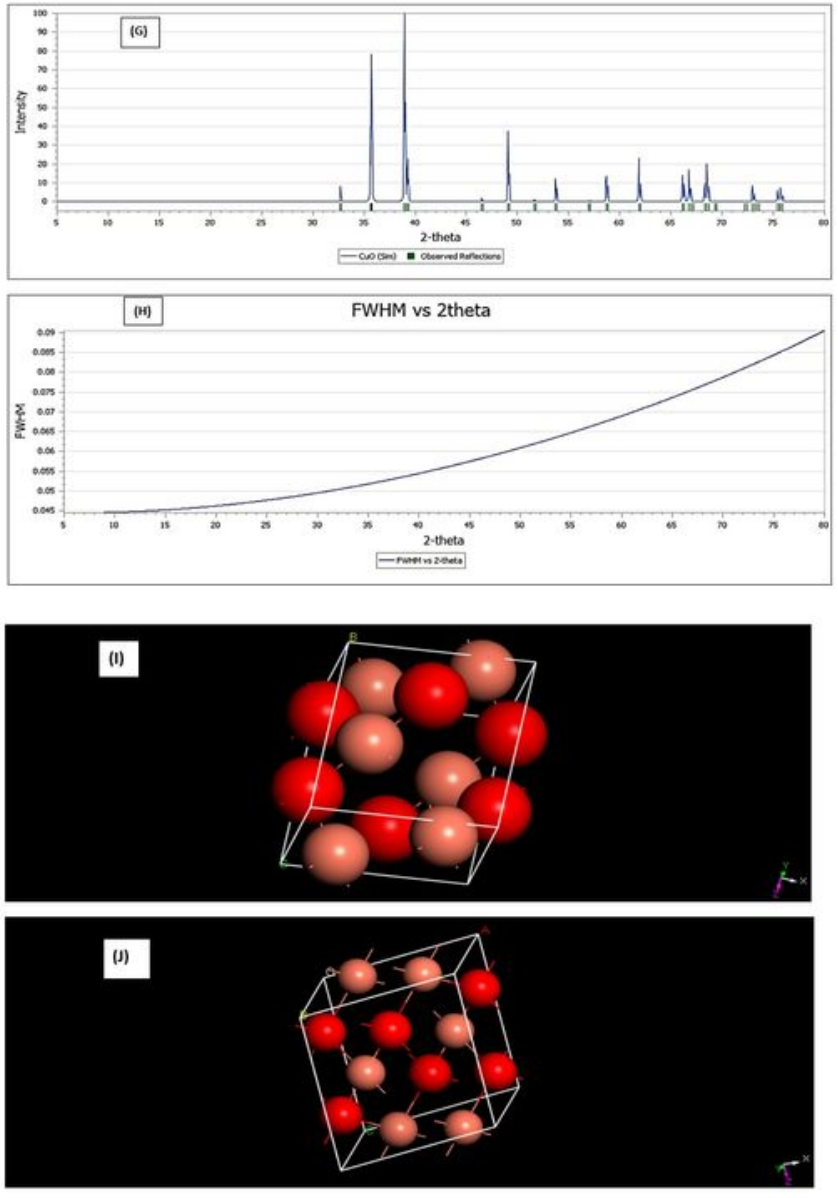

\section{.}

\section{Figure 8}

CASTEP band structure (A), CASTEP Density of States (B), Forcite X-ray intensity versus $2 \theta$ (C), Forcite Xray intensity versus scattering vector $(D)$, Forcite geometry optimization for energy $(E)$, Forcite radial distribution function $(F), X R D(G)$, Full width at half maxima versus $2 \theta(H)$, spatial distribution of atoms (I) and 3D molecular structure reciprocal lattice and Brillouin zone paths of CuO nanoparticles obtained from Materials Studio 2017 software. 

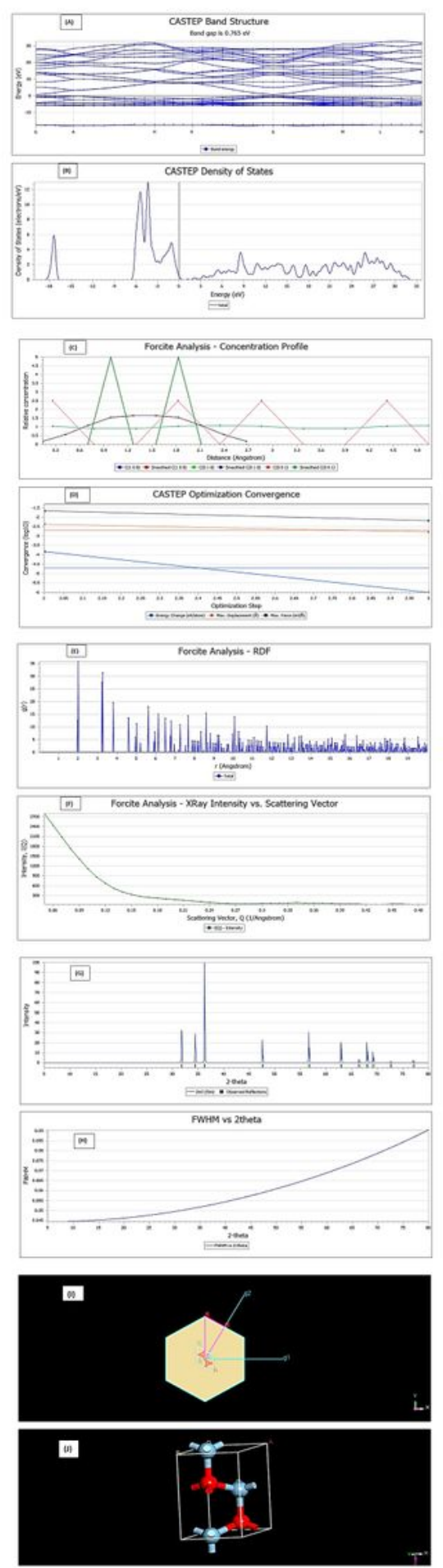

Figure 10

CASTEP band structure (A), CASTEP Density of States (B), Forcite concentration profile (C), CASTEP optimization convergence (D), Forcite radial distribution function (E), Forcite X-ray intensity versus scattering vector $(F), X R D(G)$, Full width at half maxima versus $2 \theta(H), 3 D$ molecular plane $(I), 3 D$ molecular crystal structure showing reciprocal lattice and Brillouin zone paths of $\mathrm{ZnO}$ nanoparticles obtained from Materials Studio 2017 software. 


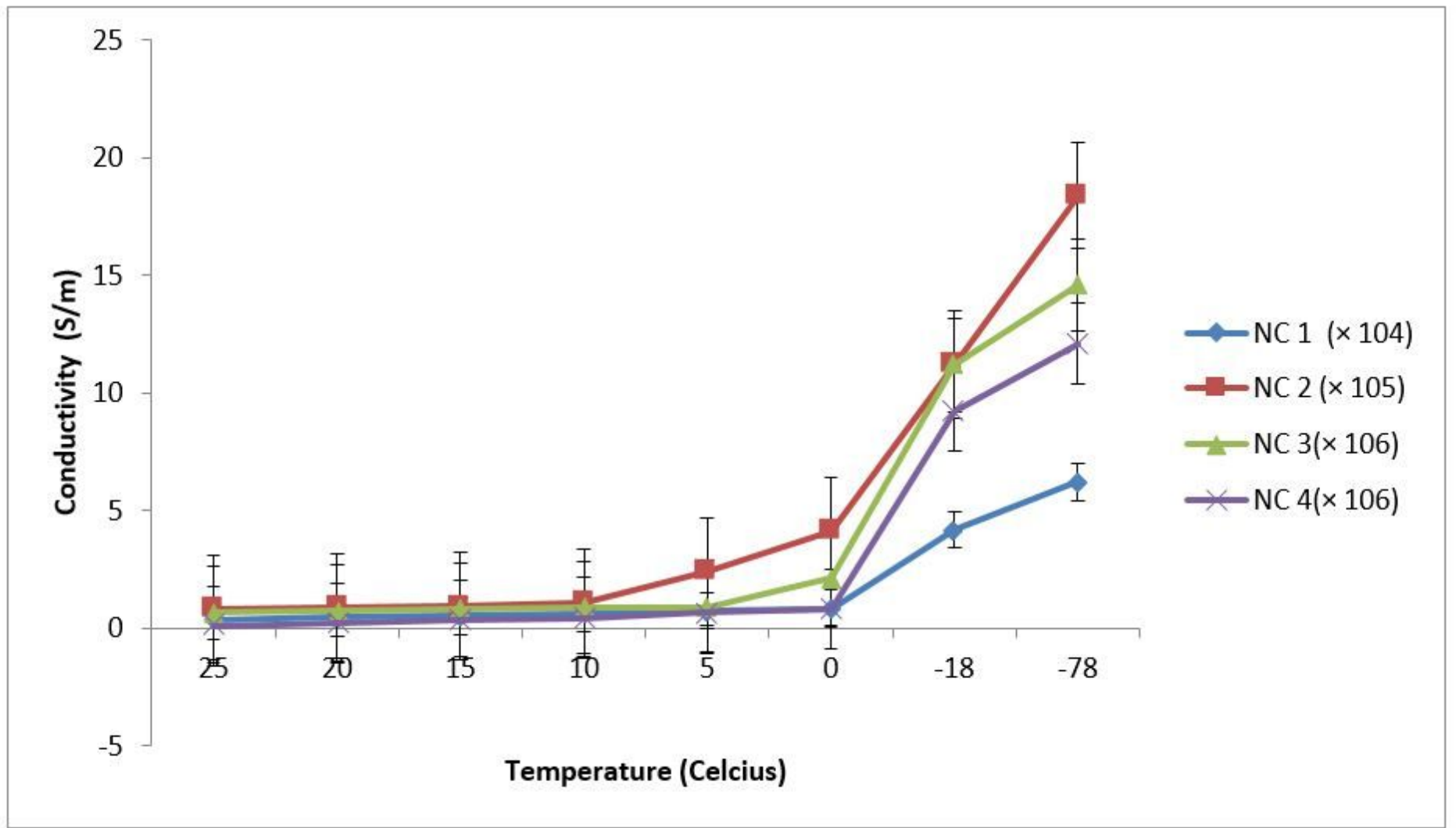

Figure 11

Variation in DC electrical conductivity of four series of Al203, ZnO, TiO2 and $\mathrm{CuO}$ (anatase) NCs with temperature. 


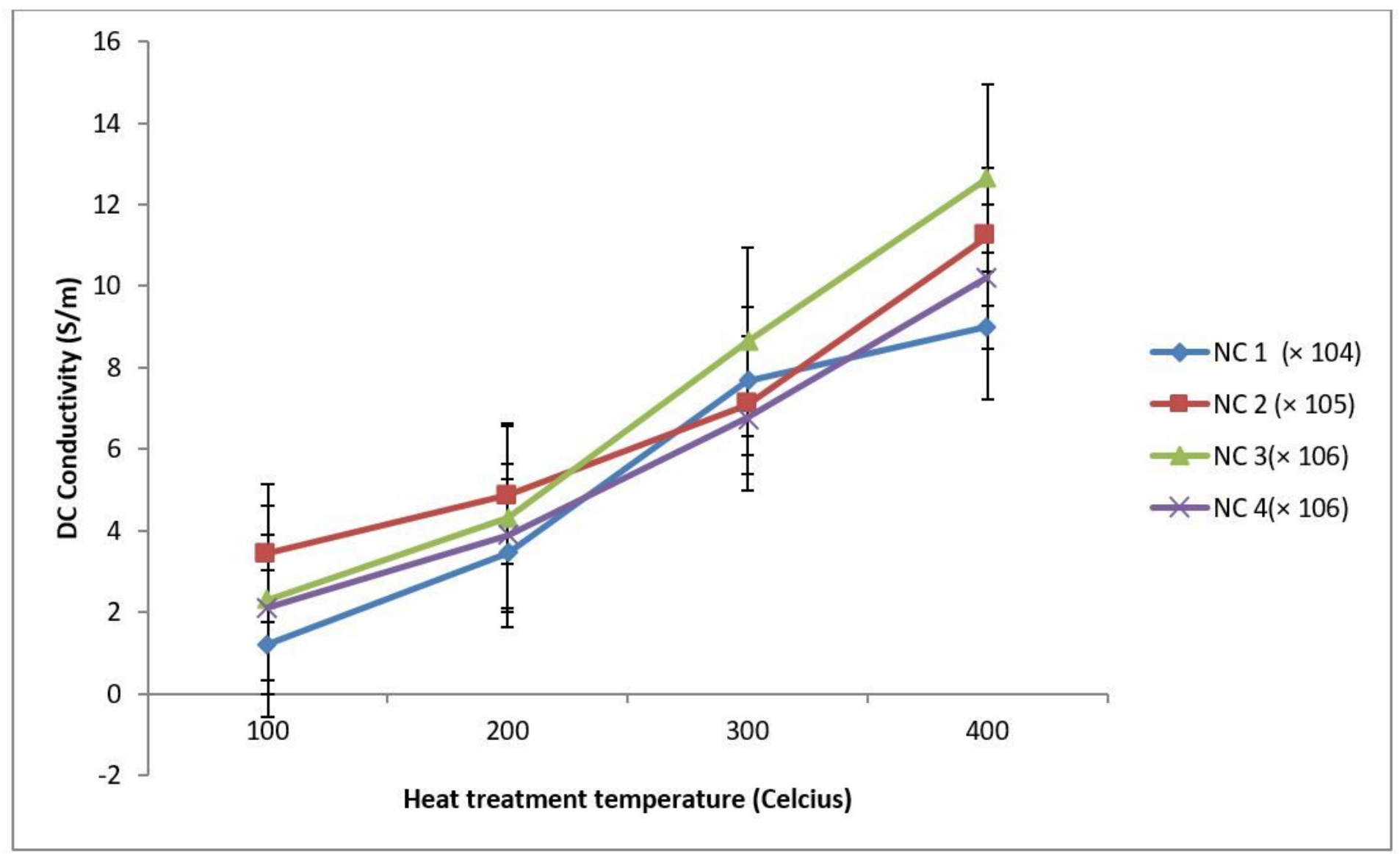

Figure 12

Variation in DC electrical conductivity of $\mathrm{Al} 2 \mathrm{O} 3, \mathrm{ZnO}, \mathrm{TiO} 2$, and $\mathrm{CuO}$ (anatase) NCs with heat treatment temperature.

\section{Supplementary Files}

This is a list of supplementary files associated with this preprint. Click to download.

- GraphicalAbstract.docx

- Al203Castepenergy.txt

- Al203DMol3.txt

- Al203Forcite.txt

- Al203BandStr.txt

- CuOCASTEP.txt

- CuOForciteenergy.txt

- TiO2anataseCASTEP.txt

- TiO2anataseDMol3.txt

- ZnOForcite.txt 
- ZnO.txt 